\title{
TOWARDS IMPROVED LEARNING OF FLUID MECHANICS VIA Integration of A Commercial SofTWARe PACKAge into AN UndergraduATE COURSE
}

\author{
Scott Campbell and David R. Latulippe \\ McMaster University, Hamilton, Ontario \\ latulippe@mcmaster.ca
}

\begin{abstract}
The integration of software packages into chemical engineering courses is widely regarded to benefit students in two ways. First, the active learning environment encourages a deep understanding of the course material. Second, it gives students practical experience with 'state of the art' tools that are used in industry. However, surveys of chemical engineering programs have shown that the use of software packages into traditional fluid mechanics courses is quite low (less than 10\%). Recently, the software package PIPE-FLO (from Engineered Software Inc.) was integrated into the second-year fluid mechanics course (ChE 2O04) at McMaster. The software performs a full hydraulic network analysis for a variety of piping configurations with numerous piping components such as pumps, compressors, and control valves. The implementation of PIPE-FLO as a simulation tool is in accordance with the recent initiative by the Canadian Engineering Accreditation Board (CEAB) to determine directions for program improvement. A set of ten self-guided tutorials were prepared to teach the students how to use the full professional version of PIPE-FLO that was available in the campus computer labs. Each tutorial was developed to enhance the understanding of the theory learned in class and included references to the appropriate equations from the course textbook. Feedback from the students was overwhelmingly positive and encouraged greater integration of the software into future offerings of the course.
\end{abstract}

Keywords: fluid mechanics, modeling, simulation, hydraulic analysis, PIPE-FLO

\section{INTRODUCTION}

\subsection{Motivation \& Problem Definition}

The ability to analyze piping systems is a key skill required of engineers in many disciplines including aerospace, chemical, civil, environmental, mechanical, and petroleum. The traditional approach to developing this skill has been to teach the fundamental equations based on the conservation of mass (i.e. continuity equation) and conservation of energy (i.e. Bernoulli equation) and then have students manually solve these equations for relatively simple cases such as a single pipe with various fittings such as valves and elbows. There are two concerns that arise from this approach. The first is that the students tend to develop only a superficial understanding of the concepts and as a result may have difficulty applying theoretical fundamentals to practical problems [1]. The second is that the analysis of such simple cases does not prepare students for the complexity of piping problems that are common in industry. In the absence of computer-based methods, an exceedingly difficult and time-consuming iterative solution would be required to solve such problems by hand [2]. Thus, a seemingly logical approach to address these two concerns is to incorporate the use of a hydraulic analysis software package into the curriculum of fluid mechanics courses [1].

Recent changes to the Canadian Engineering Accreditation Board (CEAB) criteria for accreditation require that all engineering programs measure particular attributes in their graduates in order to evaluate program effectiveness and determine directions for program improvement. By integrating a hydraulic analysis software package into the fluid mechanics course, engineering departments can show that the graduates from the program will:

1) Be able to use of modern/state of the art tools

2) $\mathrm{Be}$ able to recognize and follow engineering design principles

3) Obtain experience with open-ended problems. These three indicators are components for four of the twelve key attributes (problem analysis, investigation, design, and use of engineering tools) that have been identified by the CEAB that must be measured for program accreditation. 


\subsection{Literature Review \& Solutions Considered}

Previous research has shown that an 'active' learning environment leads to significantly higher levels of information recall over 'passive' (i.e. straight lecturing) learning [3]. A challenge for engineering education is the limited time that students are exposed to 'hands-on' laboratory exercises and thus theoretical analysis and computer simulations are appropriate tools to create an active learning process. These tools can effectively supplement the 'old fashioned' development of equations that are necessary to provide students with an appreciation of the fundamental mathematics.

For example, a core course of all chemical engineering programs is the study of equilibrium staged separations. It is now quite common for students in this course to learn chemical process simulators (e.g., HYSYS, Aspen) to complement the traditional classroom techniques such as the McCabe-Thiele approach that use graphical or pen and paper based solutions [4]. These simulations are not used to replace the manual calculations - rather as stated by Wankat [5] they are part of "an eclectic approach that includes classical graphical and analytical methods, computer simulations, and laboratory experience" to encourage a deep understanding of fundamental concepts.

There are a number of different commercially available and open-source (i.e. freeware) hydraulic analysis software packages available including AFT Fathom, PipePlan, FluidFlow3, WaterCAD, and PIPEFLO. However, despite the adoption and evidence of positive student feedback in other key chemical engineering courses [5], simulation software packages are an underused resource in the domain of fluid mechanics. A 2001 survey of US chemical engineering programs reported that less than $10 \%$ of fluid mechanics courses required the use of steady-state process simulation programs [6]. We conducted an informal survey of instructors in the fall of 2012 and found that simulation software packages were not being used in any of the fluid mechanics courses offered by other departments at McMaster nor were they being used in any of the chemical engineering programs offered at the University of British Columbia, the University of Western Ontario, McGill University, the University of Toronto, the University of Waterloo, and the University of Ottawa.

As shown in Table 1, there are alternative options to the use of hydraulic analysis software packages. For example, Hodge and Taylor [7] developed Mathcad procedures to solve problems involving series piping, parallel piping, and piping networks. The primary disadvantage of this approach is that such an approach is not widely used in industry.
Table 1 - Alternative learning activities for teaching students how to solve complex piping network problems

\begin{tabular}{|c|c|c|}
\hline Alternative & Advantages & Disadvantages \\
\hline $\begin{array}{c}\text { 'Hardy Cross' } \\
\text { calculation } \\
\text { method } \\
{[8]}\end{array}$ & $\begin{array}{l}\text { No software } \\
\text { needed, manual } \\
\text { technique }\end{array}$ & $\begin{array}{l}\text { - First published in } 1936 \\
\text { and thus definitely does } \\
\text { not satisfy CEAB attribute } \\
\text { for use of "modern/state of } \\
\text { the art tools" } \\
\text { - Limited to simple piping } \\
\text { systems } \\
\text { - Not relevant to industrial } \\
\text { settings and thus future } \\
\text { employment }\end{array}$ \\
\hline $\begin{array}{c}\text { Spreadsheet- } \\
\text { based strategies } \\
\text { (Excel) }\end{array}$ & $\begin{array}{l}\text { - Students mostly } \\
\text { familiar with } \\
\text { software } \\
\text { - Existing materials } \\
\text { for fluid } \\
\text { mechanics } \\
\text { courses are } \\
\text { available [2] }\end{array}$ & $\begin{array}{l}\text { - Not as widely used in } \\
\text { industrial settings } \\
\text { - Learning focuses on } \\
\text { setting up calculations } \\
\text { rather than understanding } \\
\text { - Limited work with open- } \\
\text { ended problems }\end{array}$ \\
\hline $\begin{array}{l}\text { Program-based } \\
\text { strategies } \\
\text { (MathCAD) }\end{array}$ & $\begin{array}{l}\text { - Existing materials } \\
\text { for fluid } \\
\text { mechanics } \\
\text { courses are } \\
\text { available [7] }\end{array}$ & $\begin{array}{l}\text { - Requires students to learn } \\
\text { program first } \\
\text { - Not as widely used in } \\
\text { industrial settings } \\
\text { - Learning focuses on } \\
\text { setting up calculations } \\
\text { rather than understanding }\end{array}$ \\
\hline
\end{tabular}

The main objective of integrating a simulation software package into the chemical engineering fluid mechanics course at McMaster University is to support students in progressing from the initial understanding of piping fundamentals gained through traditional techniques to a deeper level of learning that will foster improved competence in addressing complex industrial problems.

In comparison to the alternative learning activities listed in Table 1, we decided the learning tasks associated with the use of a commercially available software packages were found to best address the CEAB accreditation attributes and be most relevant to the needs of industry and thus future employment. Additionally, the students enrolled in the chemical engineering program at McMaster expressed a strong interest in such learning activities. In the course that was offered in the winter 2013 semester, a review of the different software package was presented to the students. An informal poll of those students revealed that over half of them were interested in learning to use such a package. A handful of students also commented on the opportunity in the course evaluations for example, one student stated "The professor hinted at the possibility of incorporating fluid mechanics software into the course. I believe this would be a fantastic idea, as well as something that could be incorporated into the students' resumes." 


\subsection{Selected Methodologies}

We conducted an assessment of the different software packages and decided that the PIPE-FLO software (from Engineered Software Inc.) would be an excellent one for students to learn how to use. According to the company's website, PIPE-FLO is used by over one hundred different companies in various fields including:

- Chemical process (BASF, DuPont)

- Food, Beverage, \& Agriculture (Cargill, Monsanto)

- Petrochemical (Chevron, Exxon)

- Pharmaceutical (Amgen, Merck, Pfizer)

- Semiconductors (HP, Intel)

Thus, it is anticipated that having students learn PIPEFLO would not only give them practical experience with 'state of the art' tools used in industry but also better prepare them for future employment in various sectors. In the most recent version of the textbook by Mott and Untener [9] there are various resources available to help with the development of in-course materials. Also, Engineering Software runs a regular series of online webinars that can be used to help the course instructors master the use of PIPE-FLO.

Engineered Software Inc. committed to providing McMaster University with fifty-two complimentary licenses of their PIPE-FLO software. A three-pronged approach to integrating PIPE-FLO into the chemical engineering fluid mechanics course ( $\mathrm{ChE}$ 2004) at McMaster University was developed; the objective was to give students exposure to the following:

1) In class examples of PIPE-FLO problems to demonstrate the utility of the program

2) Self-guided tutorials progressing gradually from a basic introduction to the software to the solving of problems of increasing difficulty

3) PIPE-FLO homework problems that will duplicate and expand on problems solved by hand in order to solidify an understanding of the methods, merits, and limitations of both approaches

\subsection{Significance of the Results}

Over the last two academic years, the implementation of the PIPE-FLO learning activity has impacted over 400 second year undergraduate students across two engineering disciplines (the course is taught to both chemical engineering and materials science and engineering students). It is anticipated that further integration of the learning activity into other fluid mechanics courses at McMaster University could impact upwards of an additional 300 students per year.

\section{THE LEARNING ACTIVITY}

\subsection{PIPE-FLO}

PIPE-FLO is a fluid flow analysis and design modeling software program. It has no limit to the number of pipelines it can handle and thus can be used to model and simulate complex piping systems for a variety of conditions. Its flexible interface provides multiple ways to view fluid systems and allows import of design data, thereby promoting a complete understanding of the entire piping system operation. For engineering students there are several other useful features within PIPE-FLO including fluid property tables, the use of process and instrumentation drawing (P\&ID) symbols to become familiar with, the ability to calculate density and viscosity as function of temperature and pressure, the availability of pipe material properties and dimensions, and the ability to calculate atmospheric pressure at various elevations. A key feature for student learning is that the software includes the catalogues for over 100 different pump suppliers. For each pump a wealth of performance data is displayed such as the minimum flow rate, the preferred operating range, pump speed, impeller diameter, net positive suction head required (NPSHr), efficiency, and power.

Fifty licences of PIPE-FLO Professional (version 12) were available in the engineering computer lab at McMaster; an additional two licences were used by the course instructor and teaching assistant. The recommended system is Microsoft Windows 7 however it will run on Microsoft Windows XP or newer desktop versions. The software can be run on a Mac but it requires a third party emulation software that would create a supported Windows environment. Also, students can download a limited demonstration version of the software from the developer's website. However, this version is limited to only five pipelines and thus is not adequate for completing all of the tutorials as described below.

\subsection{Tutorial Content \& Format}

A set of ten tutorials were prepared during the summer term of 2013. A small team of student volunteers, who had already taken the fluid mechanics course, then pilot tested the tutorial materials during the fall of 2013. Each tutorial includes detailed examples with step-by-step instructions (including the appropriate PIPE-FLO screenshots) and practice exercises. For certain tutorials, references are also made to the appropriate equations, tables, and/or figures in the current course textbook by Pritchard [2]. 
The ten tutorials were printed and sold as Custom Courseware notes (120 pages) through the McMaster University Bookstore; an electronic version was also posted on Avenue-to-Learn, McMaster's on-line learning portal.

The tutorials were designed to be completely selfguided. Lecture or tutorial time was not required for the students to master the use of PIPE-FLO. Thus, the amount of lecture time is not affected by the integration of the software. The topics for the ten tutorials are:

1) Getting Started

2) Fluid Zones and Pipe Specifications

3) Flow Between Two Tanks

4) Simulation Results \& Minor Loss

5) Reynolds Number \& Head Loss

6) Pressure Boundary, Flow Demand, \& Pressure Gradient Devices

7) Valves and Meters

8) Introduction to Pumps

9) Centrifugal Pumps

10) Piping Networks

Tutorials 1 through 5 are relatively simple and take approximately 15 to 20 minutes for the students to complete. Tutorials 6 through 10 are more involved and take approximately 45 to 60 minutes to complete.

Figure 1 shows one exercise from Tutorial 8 where the students are asked to size a pump for the transport of water from one reservoir tank to another one at a higher elevation. The students specify the pipe properties (material, size, and length), minor losses, and desired flow rate. As shown in the 'property grid' window PIPE-FLO calculates the total head, differential pressure, net positive suction head available (NPSHa), suction pressure, and discharge pressure.

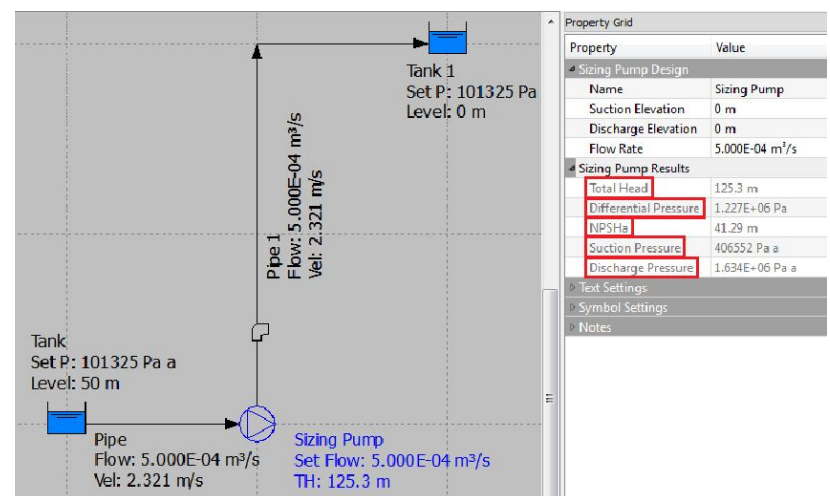

Figure 1: Pump sizing example from Tutorial 8 for the transport of water against an elevation gradient.

\section{RESULTS AND DISCUSSION}

\subsection{Implementation of the Learning Activity}

PIPE-FLO was first integrated into the ChE 2004 'Introduction to Fluid Mechanics' course at McMaster in the winter 2014 semester. It was demonstrated in approximately 5 of the 37 lectures and students were required to use it for one question on two of the six homework assignments. The feedback was quite positive (see comments in section 3.2) and many students expressed an interest for more integration of PIPE-FLO. For the winter 2015 semester, students were required to use the software for one question on three of the six homework assignments. The problem shown in Figure 2 was assigned as the first question in the fifth homework assignment. It required the students to model a bathroom piping system and determine for a given set of pressure boundaries how the water flow rate varies with different flow paths; this problem was taken from the textbook by Mott and Untener [9]. An exact copy of the question is given below:

"For this problem you will use PIPE-FLO to model a simple piping system for a bathroom and understand how flushing a toilet affects the flow rate of water in the shower.

a) Using PIPE-FLO, build the entire piping system as shown and described below. Then, determine the volumetric flow rate of water going to the shower when there is no flow into the toilet reservoir (NOTE can do this by 'closing' the pipe going to the toilet reservoir).

You must include a print-out of your FLO-sheet with the following info shown:

- For pipes: Name, Fluid Zone, Specification, Size, Length, K (Valves \& Fittings), Flow Rate, Velocity, Reynolds Number, and Pipe Friction Factor

- For pressure boundaries: Name, Elevation, Pressure, Flow Rate

b) Modify the system from part a) to determine what is the effect of flushing the toilet on the volumetric flow rate of water to the shower. Does the result match your expectation?"

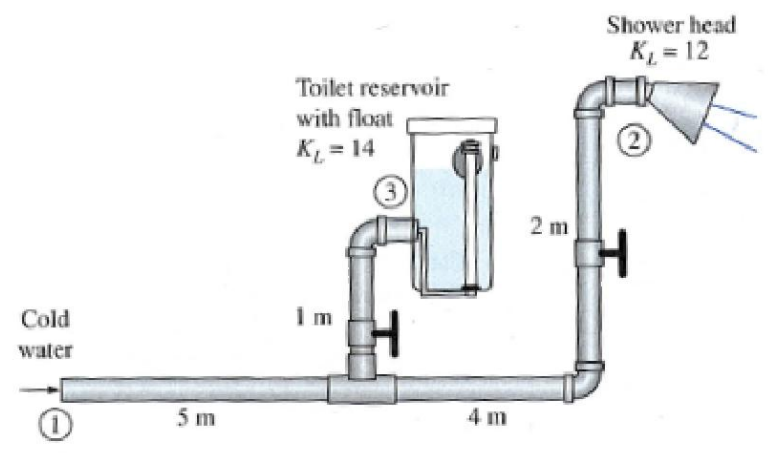

Figure 2: Layout of piping system for a question in the fifth homework assignment for the winter 2015 course; the figure was taken directly from the textbook by Mott and Untener [9]. Additional details on the pipe materials, pipe dimensions, and fitting properties that were provided in the problem statement are not given here. 


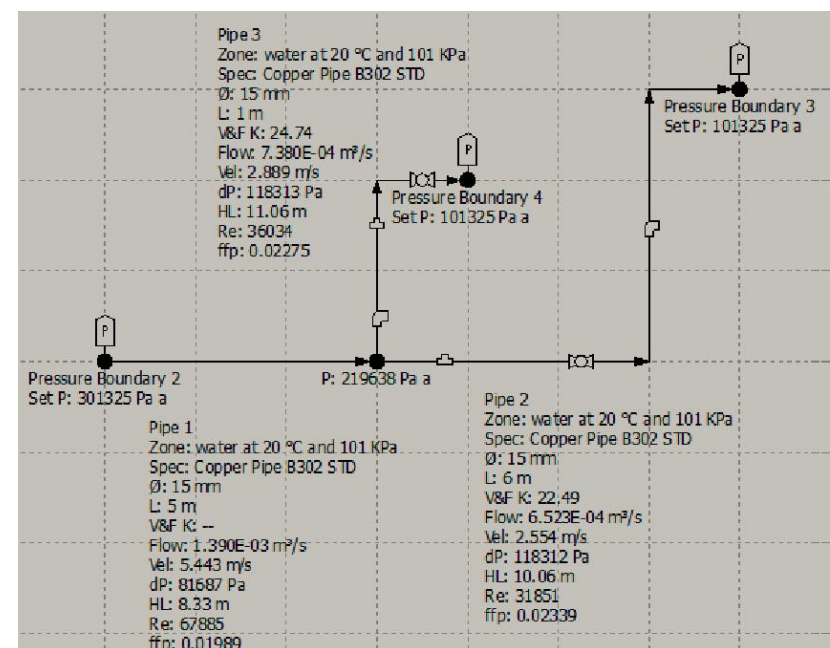

Figure 3: A screenshot of the FLO-sheet showing the solution to the problem shown in Figure 2 that was assigned as a homework problem.

\subsection{Outcome Measures}

As per the CEAB requirements, for each indicator of an attribute, the students are categorized across four levels: does not meet requirements, marginal, meets expectations, and exceeds expectations. For the fourth question on the third homework assignment from the winter 2015 semester, the students were required to use PIPE-FLO. As shown in Table 2, a total of 150 students were assessed with the majority (59\%) being in the 'meets expectations' category.

Table 2. Rubric for CEAB knowledge attribute for the indicator 'the ability to use modern/state of the art tools'. The assessment was based on the ability of the students to "use PIPE-FLO to calculate design parameters (pressure drops, flow rates, pipe sizes) for specific piping configurations that contain various types of fittings, connections, and valves".

\begin{tabular}{l|l|l}
\hline Category & $\begin{array}{l}\text { Rubric specification/ } \\
\text { expectation }\end{array}$ & $\begin{array}{l}\text { Number of } \\
\text { students in this } \\
\text { category }\end{array}$ \\
\hline $\begin{array}{l}\text { Does not meet } \\
\text { expectations }\end{array}$ & $\begin{array}{l}\text { Question not } \\
\text { attempted }\end{array}$ & 24 \\
\hline Marginal & $\begin{array}{l}\text { Question attempted } \\
\text { but got incorrect final } \\
\text { values for the design } \\
\text { parameters }\end{array}$ & 38 \\
\hline $\begin{array}{l}\text { Meets } \\
\text { expectation }\end{array}$ & $\begin{array}{l}\text { Question completed } \\
\text { with all correct values } \\
\text { for the design } \\
\text { parameters }\end{array}$ & 88 \\
\hline $\begin{array}{l}\text { Exceeds } \\
\text { expectations }\end{array}$ & N/A & N/A \\
\hline
\end{tabular}

Since questions will evolve as students gain new experiences, the monitoring of exam performance was considered insufficient to evaluate initial student learning from implementation of the PIPE-FLO learning activity. Instead, outcomes from student course evaluations were used to assess student reception of the learning activity. In the course evaluations for the winter 2014 semester, there were a total of 74 comments submitted for the topic 'please list aspects of this course that you found valuable and should be continued'; of those submissions 14 specifically mentioned PIPE-FLO and were overwhelmingly positive including the following:

○ "PIPE-FLO provided a secondary source which helped with conceptualization as well as providing us with some software experience."

- "The use of PIPE-FLO is both interesting and fun."

- "I also believe that learning PIPE-FLO will be beneficial for the future due to chemical engineers having to deal with such programs on a daily basis."

- "The PIPE-FLO is interesting and should be kept."

- "The introduction of PIPE-FLO was a great feature and should definitely be continued."

- "PIPE-FLO provided a very interesting perspective of the course material, showing the practical applications of the material."

- "Getting experience with PIPE-FLO was very interesting."

- "I enjoyed how there were so many different learning resources that were made available to students."

- "I really liked using PIPE-FLO, it is awesome software."

\subsection{Future Developments}

Two strategies are under consideration to further the students' ability to use and master the use of PIPE-FLO as a hydraulic analysis software package. The first is to add a final design project into the ChE $2 \mathrm{O} 04$ course; this task would challenge the students with a problem of similar complexity that they would likely encounter in an industrial setting. The second is to integrate PIPE-FLO into the fourth-year $\mathrm{ChE} 4 \mathrm{~N} 04$ 'Engineering Economics and Problem Solving' course. A classic engineering example is to select a pump for a given application based on an optimization of design and operating cost criteria. The 'pump selection' program in PIPE-FLO allows the user to calculate the energy and life cycle costs according to different pump options such as impeller diameter and pump speed.

Finally, we will develop a new rubric for the CEAB attributes that will allow students to be categorized across all four levels. 


\section{CONCLUSIONS}

PIPE-FLO has been successfully integrated into the chemical engineering fluid mechanics course (ChE 2O04) at McMaster University through the use of tutorials, inclass examples, and homework assignments. The set of ten tutorials were designed to be completely self-guided and thus there was very little impact on the amount of lecture time needed for other course content. Each tutorial includes detailed examples with step-by-step instructions, practice exercises, and references to the appropriate equations, tables, and/or figures in the course textbook. Over the last two academic years, over 400 second year undergraduate students across two engineering disciplines have been impacted by this initiative and the student comments in the course evaluations have been overwhelmingly positive. The implementation of PIPE-FLO as a simulation tool is in accordance with the recent initiative by the Canadian Engineering Accreditation Board (CEAB) to determine directions for program improvement. An assessment based on the ability of the students to "use PIPE-FLO to calculate design parameters (pressure drops, flow rates, pipe sizes) for specific piping configurations that contain various types of fittings, connections, and valves" found that the majority of those students (59\%) were in the category specified as 'meets expectations'.

\section{ACKNOWLEDGEMENTS}

Engineered Software Inc. for providing the fifty-two complimentary licenses of PIPE-FLO. Pedro Ivo de Oliveria Filho developed the original set of PIPE-FLO tutorial materials. The McMaster Institute for Innovation and Excellence in Teaching and Learning (MIIETL), formerly known as Center for Leadership in Learning, provided the seed funds for this project in the form of a Teaching and Learning Grant. From the chemical engineering department at McMaster, the authors thank Dan Wright for his assistance with the implementation of PIPE-FLO and the following undergraduate students who volunteered to pilot test the tutorial materials: Weilin $\mathrm{Hu}$, Rihong Zhang, Dominic Chan, Chris Wang, and Muhammad Danish Fazal.

\section{REFERENCES}

[1] Jason Keith, David Silverstein, Donald Visco, "Ideas to consider for chemical engineering educators teaching a new 'old' course: freshman and sophomore level courses" Proceedings of the 2008 American Society for Engineering Education Annual Conference \& Exposition, 2008-1147.

[2] Phillip J. Pritchard, Fox and McDonald's Introduction to Fluid Mechanics. 8th Edition. John Wiley \& Sons, 2011, $896 \mathrm{pp}$.

[3] H.C.A. Dale, "Response availability and short-term memory" Journal of Verbal Learning and Verbal Behavior, 6 (1), 1967, 47-48.

[4] Kevin D. Dahm, "Process simulation and McCabe-Thiele modeling", Chemical Engineering Education, Spring 2003, 132-141.

[5] Phillip C. Wankat, "Teaching separations - why, what, when, and how?" Chemical Engineering Education, Summer 2001, 168-171.

[6] Kevin D. Dahm, Robert P. Hesketh, and Mariano J. Savelski, "Is process simulation used effectively in $\mathrm{ChE}$ courses?" Chemical Engineering Education, Summer 2002, 192-198.

[7] B.K. Hodge and Robert P. Taylor, "Piping-system solutions using Mathcad" Computer Applications in Engineering Education, 10, 2002, 59-78.

[8] Hardy Cross, "Analysis of flow in networks of conduits or conductors", University of Illinois Engineering Experiment Station, 1936, Bulletin 286.

[9] Robert L. Mott and Joseph A. Untener, Applied Fluid Mechanics. $7^{\text {th }}$ Edition. Prentice Hall, 2014, 552 pp. 